\title{
PERCEPÇÕES DOS PACIENTES QUANTO AOS PROCEDIMENTOS INVASIVOS NO PÓS-OPERATÓRIO DE CIRURGIAS DE GRANDE PORTE*
}

\author{
Maria Eunice Medeiros Teixeira** \\ Maria Alves Barbosa***

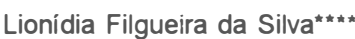

\begin{abstract}
RESUMO: Estudo descritivo, com abordagem qualitativa, onde as percepções dos pacientes submetidos a cirurgias de grande porte, em relação aos procedimentos invasivos, foram objetos centrais. O local onde o estudo se desenvolveu foi a clínica cirúrgica de um hospital de ensino em Goiânia. A população constituiu-se de pacientes submetidos de procedimentos invasivos de ambos os gêneros, com faixa etária entre dezoito e sessenta e nove anos. A entrevista semi-estruturada e a observação direta foram utilizadas para a coleta de dados. Os resultados apresentados em três categorias, evidenciaram pouca orientação e interação profissionais-pacientes. A sonda nasogástrica foi o procedimento invasivo que mais incomodou o grupo pesquisado. Aspectos não esperados referentes ao tratamento foram também descritos neste estudo.
\end{abstract}

ABSTRACT: This is a qualitative descriptive study carried out in a hospital-school of Goiânia, on the reaction to invasive procedures of pacients who had undergone major surgeries. Both sexeswere studied ( ages between eighteen and sixty-nine) through semistructured interviews and through direct observation. The results show that little orientation was given to the patients, and that no interaction between professionals and patients took place. The nasal-gastric catheter was the least accepted procedure. Other unexpected results are also discussed.

\section{UNITERMOS: Procedimentos Invasivos - Cirurgias de Grande Porte - Percepção}

\section{CONSIDERAÇÕES INICIAIS}

A evolução tecnológica na área da saúde nas últimas décadas, traz consigo facilidades tais como rapidez e precisão no diagnóstico e tratamento das patologias, mas ao mesmo tempo, acompanha-se de algum desconforto para o paciente. É o caso por exemplo das incisões e outros procedimentos invasivos, que tendem a se tornarem rotineiros na moderna medicina, apesar de existir muita polêmica em tomo de sua utilização, e mesmo recomendações de cautela ${ }^{3,7}$.

PADILHA ${ }^{18}$ considerou como procedimentos invasivos, os instrumentos inseridos no organismo do paciente através de orifícios naturais ou artificiais, os que rompiam suaintegridade cutâneomucosa e aqueles que invadiam seu espaço corporal, mesmo que não houvesse contato físico direto.

BOGOSSIAN $^{3}$ cita como agressões na fase

* Trabalho apresentado como Tema Livre no $45^{\circ}$ Congresso Brasileiro de Enfermagem. Olinda-Recife, 28 de novembro a 3 de dezembro de 1993.

** Mestre em Enfermagem, docente do Departamento de Enfermagem da Faculdade de Enfermagem e Nutrição da Universidade Federal de Goiás.

*** Mestre em Enfermagem, docente do Departamento de Enfermagem da Faculdade de Enfermagem e Nutrição da Universidade Federal de Goiás e enfermeira do Hospital de Clínicas da Universidade Federal de Goiás.

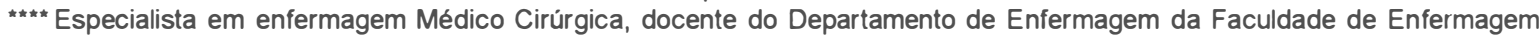
e Nutriçăo da Universidade Federal de Goiás. 
pós operatória as sondagens, os cateterismos, as injeções endovenosas e intramusculares.

BIROLINI ${ }^{2}$, referindo-se a procedimentos invasivos, afima que o pós-operatório de cirurgia de grande porte implica na inserção de catéteres, cânulas, sondas, drenos e ministração de soluções. Ainda segundo o referido autor, estes procedimentos, embora de pequeno porte, são de natureza invasiva e dolorosos, levando os pacientes muitas vezes a situações constrangedoras, que os agridem tanto física como psicologicamente.

Entretanto, alguns estudos apesar de exaustivos, não abordam especificamente as reações $\mathrm{e}$ percepções dos pacientes portadores de procedimentos invasivos, $2,3,17$

Muitos trabalhos que tratam do preparo préoperatório enfatizam a necessidade de se evitar infecções e/ou complicações no período pósoperatório ${ }^{3,6,9,10 .}$

Segundo BARBOSA ${ }^{1}$, a finalidade precípua doscuidados pré-operatóriosimediatosé contribuir para o conforto e segurança do paciente cirúrgico. Para VALLE etal. ${ }^{29}$, além dos cuidados físico e da realização dos exames de rotina, o enfermeiro deverá incluir o preparo psicológico do paciente, explicando-Ihe como serão as fases do trans e pós-operatórios.

Este estudo surgiu da nossa inquietação enquanto docentes, acompanhando alunos na assistência a pacientes submetidos a grandes cirurgias num hospital de ensino. Muitas vezes nos deparamos com pacientes apresentando diferentes reações no pós-operatório, tais como choro, stress, admiração, decepção, em decorrência da utilização de procedimentos no ambulatório, e nem sempre estamos na clínica no momento da internação, começamos a nos questionar : será que o preparo pré-operatório realizado no hospital inclui esclarecimento quanto ao pós-operatório, e mais especificamente, quanto aos métodos invasivos? O que assusta mais, a cirurgia em si, ou a fase pós-operatória? Como os pacientes reagem e percebem os procedimentos invasivos a que se submeteram? (o preparo pré-operatório preconiza orientações referentes aos aspectos físico, mental, social e psicológico ).

Tentando conhecer melhor estas respostas e as percepções dos pacientes portadores de procedimentos invasivos, dispusemo-nos à realização deste estudo, com o objetivo de apreender as percepções dos pacientes no pós-operatório de cirurgias de grande porte, em relação aos procedimentos invasivos.

\section{OS CUIDADOS PRÉ E PÓS-OPERATÓRIOS}

Nos dias atuais, muito se tem escrito sobre os cuidados pré e pós-operatórios

O período pré-operatório, segundo KAWAMOTO ${ }^{10}$, inicia-se nainternação e termina momentos antes da cirurgia, tendo como finalidade, a rápida recuperação e redução de complicações. No pós-operatório pode-se também "detectar e prevenir a instalação de complicações". De acord o com BARBOSA ${ }^{1}$, cronologicamente o período pré-operatório abrange as primeiras vinte e quatro a quarenta e oito horas, enquanto que no pós-operatório existem as fases precoce, tardia e de convalescença.

A adaptação física e psicológica do paciente ao ambiente hospitalar poderá acontecer no período pré-operatório, quando houver tempo e condições para que isto ocorra. BRUNNER e SUDDARTH ${ }^{5}$ referem como objetivo do préoperatório "levar o paciente à melhor condição física e psicossocial possivel, tendo em vista a cirurgia". Os meios para se conseguir este objetivo, continuam as autoras, são determinados pelas necessidades individuais do paciente. Afirmam que o pós-operatório consiste em auxiliar o paciente a retornar normalmente às suas funções.

Além da prevenção de infecções, o pré-operatório consiste, na visão de BOGOSSIAN ${ }^{3}$, em colocar os órgãos, aparelhos e sistemas envolvidos na cirurgia, em repouso e condições basais. Para este autor o pós-operatório é o período compreendido entre a saída do paciente da cirurgia, até 0 retorno às atividades normais. Ele classifica este período como imediato, mediato e tardio.

Ultimamente tem-se preconizado as visitas pré e pós-operatórias realizadas pelos enfermeiros de Centro Cirúrgico 20,27,28,29.

Sob o ponto de vista de ROZA ${ }^{22}$, para as visitas no pré-operatório, o enfermeiro utiliza-se dos prontuários, da observação direta e da entrevista e estas têm por finalidade detectar problemastanto do paciente, quanto da sua família, para planejar, dirigir, executar supenvisionar e avaliara assistência prestada". No pós-operatório, elas são realizadas após trinta e seis a quarenta e oito horas do ato cirúrgico. 
A visita pré-operatória na visao de PELLIZZETTI \& BIANCHI ${ }^{20}$ contribui, entre outros aspectos, para reduzir a ansiedade do paciente, oportunidade na qual ele pode explicitar angústia, dúvidas e expectativas. Sobre este aspecto foram encontrados trabalhos que abordam percepções dos pacientes a respeito do ambiente hospitalare mais especificamente, sobre cirurgias. ${ }^{11,12,24}$

Mesmo em pacientes bem esclarecidos quanto aos procedimentos que envolvem o ato cirúrgico, o período anterior à cirurgia causa certa ansiedade e traz expectativas. Sobre este aspecto, TEIXEIRA ${ }^{25}$ lembra quanto à necessidade de assistência integral. Para RODRIGUES ${ }^{21}$ , além de informações referentes aos próprios procedimentos terapêuticos, o relacionamento humano deve ser valorizado e SALZANO ${ }^{27}$ considera comunicação um componente essencial para esse trabalho.

A assistência no pré e pós-operatórios abrange não apenas cuidados físicos, como psico-sociais e espirituais, e em ambos os períodos torna-se relevante a assistência individualizada.

A essência da prática de enfermagem no que se refere à ajuda ao paciente envolve a compreensão do que acontece entre o profissional e ser assistido ${ }^{16}$. Assim sendo, impõe-se ao enfermeiro, reflexões sobre os aspectos intervenientes no relacionamento terapêutico, buscando soluções para as dificuldades pertinentes a esse processo.

Interações efetivas nas visitas pré e pósoperatórias geram satisfação. Se a interação for bloqueada por inabilidade do profissional e/ou ansiedade do paciente, esta satisfação não será alcançada.

\section{METODOLOGIA}

As percepções da clientela que se submeteu a cirurgias de grande porte e que foi portad ora de procedimentos invasivos constituíram-se em objetoscentrais deste estudo. Outraquestãotambém considerada relevante para a pesquisa, foi 0 preparo do paciente para a cirurgia. Para tanto, optamos pela realização de um trabalho de campo, denatureza descritiva, comabordagem qualitativa. Acreditamos que este foi o melhor caminho para a consecução do objetivo, devido ao tipo de problema colocado, à forma como os sujeitos foram abordados e ao método de tratamento dos resultados da pesquisa.
O estudo se desenvolveu em um hospital integrante da rede pública, localizado em Goiânia, escolhido porque ali se realizam grandes cirurgias. A equipe de saúde contém elementos em quantidade considerada adequada ao número de leitos, e além disto, esta unidade serve como campo de estágio para alunos de diversos cursos, entre eles, os de enfermagem. Estes aspectos motivaram e facilitaram a coleta de dados.

Os sujeitos deste estudo foram os pacientes internados na Clínica Cirúrgica do referido hospital, que se submeteram a cirurgia de grande porte e que foram portadores de sondas vesical, nasogástrica, drenos de Penrose, Kher etorácico, punção venosa profunda e periférica.

A coleta de dados foi realizada pelas pesquisadoras, nos turnos matutino e vespertino. Os procedimentos utilizados foram a entrevista individual realizada na própria enfermaria e a observação direta. Decidimo-nos pela entrevista do tipo semiestruturada, que segundo TRIVIÑOS ${ }^{26}$, ao mesmo tempo que valoriza a presença do investigador, oferece todas as pespectivas possiveis para que o informante alcance a liberdade e espontaneidade necessárias, enriquecendo a investigação. Foi elaborado um roteiro de perguntas abertas, o qual permitia a flexibilidade necessária para que, tanto 0 investigador quanto o informante pudessem completar, corrigir ou adaptar suas informações. O registro cursivo foi utilizado para armazenar as anotações referentes às entrevistas.

De acordo com LUDKE \& ANDRÉ ${ }^{13}$, a observação direta permite que o observador chegue mais perto das pespectivas dos sujeitos, constituindo-se num importante alvo nas pesquisas qualitativas. Para estas autoras, enquanto o pesquisador acompanha in loco as experiências dos sujeitos, ele pode apreender suas percepções e o significado que atribuem à realidade.

Neste estudo, para evitar visão parcial e tendenciosa, fizemos a confrontação do que fomos captando da realidade, com o que esperávamos encontrar das primeiras idéias com aquelas que foram surgindo mais tarde. Procedemos ainda, à confrontação das primeiras anotações com os registros feitos ao longo do estudo, tal como recomendam Guba \& Lincoln, citad os por LUDKE \& ANDRÉ ${ }^{13}$. Os registros das observações das pesquisadoras constaram do cademo de campoe foram realizados no momento mais próximo da observação, para conferir maior precisão aos da- 
dos.

A pesquisa qualitativa adota a análise dos resultados paralela à coleta e isto permitiu, neste estudo, a inclusão de novas questões de investigação e/ou cancelamento de outras. Retornamos várias vezes ao campo para completar, corrigire adaptar informações junto aos pacientes.

A fase mais formal da análise nos estudos qualitativos, tem lugar quando a coleta de dados está encerrada ${ }^{13}$, e implica em organizar o material, dividí-lo em partes, estabelecer relações entre elas e investigar neste material, tendência e alterações importantes. Num segundo momento, conforme LUDKE \& ANDRÉ ${ }^{13}$, " essastendências e padrões são reavaliados, buscando-se relações e inferências num nível de abstração mais elevado".

Para garantir validade à pesquisa, checamos os resultados através de situações, momentos ocorridos na enfermaria e também revelamos os diferentes pontos de vida dos sujeitos do estudo ${ }^{13}$.

A avaliação dos resultados ocorreu com a apresentação do relatório final da pesquisa à maioria dos informantes. Osclientesque estavam presentes na enfermaria, que também se submeteram a grandes cirurgias e foram portadores de procedimentos invasivos, mas que não participaram do estudo, consideravam "como seus" os depoimentos dos clientes entrevistados, mostrando que também concordavam com a interpretação dos resultados.

\section{RESULTADOS E DISCUSSÃO}

\section{1 - Caracterização dos sujeitos do estudo}

O grupo de sujeitos deste estudo constituiu-se de paciêntes com faixa etária variando entre dezoito e sessenta e nove anos.

Quanto ao grau de instrução, alguns eram nãoalfabetizados, outros possuiam o $1^{\circ} \mathrm{grau}$ incompleto, enquanto outros cursaram $2^{\circ}$ grau.

Entre as profissõesque o grupo exercia, identificamos: metalúrgicos, secretários, datilógrafos, técnico em agrimesura, e do lar. Estes pacientes se submeteram a cirugias de grande porte a saber: gastrectomia, histerectomia, Duhamel $1^{\circ}$ tempo, coledocolitotomia, enterectomia, laparotomia com cistopexia e laparotomia com drenagem torácica bilateral. As cirugias de grande porte foram classificadas de acordo com a Tabela de Grupos e Procedimentos do Instituto Nacional de Assistência Médica e Previdência Socia' ${ }^{4}$. Estas cirugias também foram referidas por TEIXEIRA ${ }^{25}$ como de grande portes. Todos os clientes que participaram deste estudo foram submetidos a procedimentos invasivos. Além da incisão cirúrgica, possuiam sondas nasogástricas, vesicais, drenos de penrose, Khere torácico, punção venosa profunda e periférica, coto perineal e sonda retal.

\section{2 - As Percepções}

\section{Sentindo desconforto em relação dos procedimentos invasivos}

Procedimentos invasivos constituem fonte de desconforto, que variam de acordo com o procedimento e o tipo de intervenção realizada. Conhecer estes desconfortos implica em melhorar a qualidade de assistência prestada. VALLE et al. ${ }^{29}$ referindo-se ao preparo para a cirurgia cardíaca, afirmam que o paciente deve ser orientado quanto à anestesia, ventilação artificial, utilização de tubos, sondas, catéteres, monitorização cardíaca, exercícios respiratórios, possibilidades de dor e administração de medicamentos. Ficou evidenciado no presente estudo, o desconforto causado por estes procedimentos:

"Em relação aos drenos e tubos a gente tem vontade de retirar, mas não retira, porque sabe que não pode".

De acordo com MOSCOVICl ${ }^{15}$, existem diferenças individuais na maneira de pensar, perceber, sentire agir. Entre os pesquisados, percebemos que um mesmo tipo de procedimento invasivo (sonda nasogástrica), provocou em pacientes diferentes, também reações adversas. Algunssentiram irritação na garganta, enquanto outros queixaram-se de angústia e nervosismo, conforme se podeconfimar:

"Sentivontade de retirar a sonda nasogástrica por sentir dor e irritação na garganta, então o médico me orientou a respeito".

"Quando vi que estava com a sonda no nariz, fiquei mais ruim do que estava".

"A sonda dá muita fadiga".

"Quando senti aquela mangueira na minha garganta, sem poder conversar, fiquei muito nervoso; ficava mais nervoso ainda quando queria levantar e ela me atrapalhava". 
Apesar de causar reações diferentes, o desconforto provocado pela sonda nasogástricafoi comun em todos os pacientes entrevistados. Ela é rotineiramente prescrita para eliminar gases, sangue ou secreções, e também evitar vômitos no pós-operatório imediato de cirurgias do apareIho digestivo.

Prestar informações específicas ao paciente sobre as sensações esperadas, pode ser útil. Contudo, é importante antes de fornecerqualquer informação, ouvir o paciente, seus temores e dúvidas. À medida que o paciente possui conhecimentos a respeito da cirurgia, ele poderá melhor enfrentar a situação estressante em que se encontra.

Algumas das observações feitas ao longo deste estudo, coincidem com aquelas apresentadas porROZA et al. ${ }^{22}$, onde os pacientes, na sua maioria, são submissos, humildes e pouco exigentes. Quando indagados sobre o tratamento oferecido, respondem:

"Não tenho nada a queixar, tratam a gente bem".

Além do desconforto físico, um dos pacientes entrevistados, portador de coto perineal, sentiase deprimido por perceberque involuntariamente incomodava seus colegas internados na mesma enfermaria:

"Parece que a gente precisava ser melhor orientado para esta falta de controle da emissão de fezes. A gente sente-se deprimido, angustiado, porque gostaria de evitar que nossos vizinhos de leito viessem a inalar odores desagradáveis".

Este paciente demonstrou sentir repugnância de si mesmo. Verbalizou vontade de ter alta para que pudesse se higienizar melhor. Este tipo de depoimento revela a necessidade de orientações, palavras de conforto, contribuindo para o paciente refletir, aceitar a ajuda da equipe de saúde e as limitações impostas pela cirurgia, uma vez que temporariamente dependerá de outras pessoas.

\section{3 -Apreendendo e repassando experiências de colegas de quarto}

Vários estudos, entre eles o de BRUNNER \& SUDDARTH ${ }^{5}$, URSI \& MACUL ${ }^{28}$,PASCUCCIZEN \& BRUTSCHER ${ }^{19}$, SALZANO $^{27}$, JOUCLAS \& SALZANO ${ }^{8}$ têm evidenciado que as orientações pré e pós-operatórias podem contribuir para a redução da ansiedade pela qual passam os pacientes cirúrgicos.

De acordo com PASCUCCIZEN \& BRUTSCHER ${ }^{19}$, a situação de conflito em que se encontra o paciente de cirurgia, decorre da incerteza, desconhecimento, desconfiança e falta de apoio quando busca amparo e solução para os seus problemas.

Entretanto, as experiências próprias adquiridas de cirurgias anteriores a que se submeteram os pacientes, parecem conferir-Ihes mais confiança quando expostos a uma cirurgia posterior, conforme revelam os depoimentos:

"Já tinha me submetido a outras cirurgias".

"Quando cheguei do centro cirúrgico e me vi com tudo isto, senti a maior tranquilidade; o meu estado de espírito é de entusiasmo".

Embora considerando que não recebeu esclarecimentos no pré-operatório, o cliente explicitou:

"Ninguém falou nada a respeito da cirurgia. Ao me ver com todas estas sondas, não senti nada, achei tudo natural no momento".

Há outros pacientes que mesmo recebendo orientações pré-operatórias, não as consideraram suficientes:

"Fiquei de nove a dez dias fazendo o préoperatório, mas permaneci mal esclarecido por deficiência própria".

Muitos pacientes relataram que embora não tenham recebido orientações da equipe de saúde, encontraram outros pacientes na mesma enfermaria que haviam passado por aquela experiência e os ajudaram a superar a ansiedade e o temor pelos procedimentos cirúrgicos:

"A gente sempre fica preocupada, não fiquei muito, pois na enfermaria já tinha muitas pacientes operadas e me explicaram como era".

"As outras pacientes da enfermaria já tinham colocado sonda e, me falaram que não era nada; era coisa à toa".

"Outros pacientes que tinham passado pela mesma cirurgia, permitiram que eu visse e fiquei me preparando para o que vinha".

Os depoimentos revelaram que os pacientes também gostam de contribuir com os outros na mesma situação:

"Pude ajudar alguns pacientes. Não éa primeira vez que isto acontece comigo. Já estive hospitalizado e tive o prazer de ajudar alguém".

A presença de familiares oferece conforto e segurança mesmo nos casos de pacientes relutantes ao tratamento. 
"Meu pai, minha mãe, minha família me ajudaram bastante".

"Penseivárias vezes em tirar a sonda do nariz, Meu paique estava me acompanhando me aconselhou bastante para não fazer aquilo".

A ajuda mútua entre pacientes de uma mesma enfermaria e a comunicação estabelecida entre eles, já foram relatadas por outros estudos, ${ }^{11,15}$.

A relação estabelecida entre pacientes exoperados e bem sucedidos com aqueles que irão se submeter às mesmas cirurgias, pode oferecer segurança a este novo paciente.

\section{4-Explicitando necessidade de orientações pré e pós-operatórias}

Procedimentos cirúrgicos significam ameaça à integridade física, desconforto, ansiedade e medo do desconhecido, sendo então necessária a orientação da equipe de saúde. Segundo SALZANO ${ }^{27}$, considera-se de grande risco aquele paciente excessivamente temeroso. Vários estudos têm abordado a responsabilidade do enfermeiro quanto ao preparo pré e pós-operatóriOS. $5,12,19,25,27,28,29$

Neste estudo houve relatos de pacientes que se ressentiram da falta de orientações para a cirurgia:

"Não tive nenhum preparo; ninguém orientou nada. Ninguémexplicou nada".

"A equipe de enfermagem não explica nada quando as pacientes reclamam das sondas, soros, mas são solícitas quando são chama- das".

"Parece que a gente precisava ser melhor orientado".

SOARES ${ }^{23}$ afirma que um bom relacionamento entre enfermeiro e paciente reduz o impacto da cirurgia e as possibilidades de complicações, além de promover adaptação mais rápida. Entretanto, alguns pacientes do nosso estudo, admitiram que não receberam apoio quando sentiam algum desconforto decorrente dotratamento.

"Quando estavanervoso, ansioso porcausa da sonda, ninguém me ajudou. So aconteceu".

"Ninguém me deu uma plavra de conforto".

Os pacientes demonstraram que gostam de ser atendidos por pessoas alegres e comunicativas:

"Os enfermeiros atendiam bem, sóque alguns tinham a cara fechada. É tão bom quando se ouve um bom dia! A gente sente mais confiança".
Nesse sentido, TEIXEIRA ${ }^{25}$, SOARES ${ }^{23}$ e RODRIGUES ${ }^{21}$ enfatizam 0 tratamento humanizado.

\section{5 - Resultados inesperados}

Quando indagados sobre quais aspectos da cirurgia mais os assustavam, um cliente respondeu:

"O que tive mais medo foi do atendimento do pessoal do hospital, porque a gente houve falar muitas coisas ruins". E acrescentou: "mas no Pronto Socorro (do próprio hospital) os enfermeiros atendiam bem".

Outro assim argumentou:

"Eu só tenho medo de me entregar nas mãos de pessoas não especializadas".

Por outro lado, alguns pacientes reconhecem que existem pofissionais que correspondem às suas expectativas:

"Existem enfermeiras que trabalhamtantoemocional quanto profissionalmente. Relacionam-se Dem como enfermo", o que vem ao encontro de PASCUCCIZEN\&BRUTSCHER ${ }^{19}$ quando afimam que "o paciente espera solução para os seus problemas por parte daquelesqueteriam obrigação profissional e institucional de reconhecê-los e solucioná-los".

Existem outros aspectos que também assustam os pacientes e dizem respeito aos procedimentos adotados, tais como, medo da dor, da incisão, dos drenos:

"Ainda bem que não sabia disto".

"Quando acordei já estava com a sonda".

Entretanto, como colocado anteriormente, o medo da sonda nasogástrica foi o que mais se destacou neste estudo. VALLE et al., 29 afirmam que no preparo para cirurgias devem ser dadas orientações quanto aos procedimentos invasivos de maneira clara, objetiva, de acordo com o nível cultural do paciente. Todavia, URSI \& MACUL, ${ }^{28}$ relatando experiência com visitas pré e pósoperatórias, comentam que, para não provocar medo antecipado, esclarecem apenas aquelas questões que o paciente aborda, ou quando os procedimentos envolvem mutilações, como é o caso das cirurgias mutilantes. Em principio, isto nos parece omissão de orientações, mas conforme ilustram os depoimentos acima, alguns pacientes 
não gostariam de saber antecipadamente das sensações que irão experimentar a respeito dos procedimentos invasivos, e seriam portanto, favoráveis à atitude das autoras.

\section{CONSIDERAÇÕES FINAIS}

Os resultados revelaram que a maioria dos pacientes submetidos a sondas, catéteres e drenos de vários tipos, talvez devido à ausência de informações, demonstrou ansiedade e insegurança em relação ao tratamento.

Apesar de relevantes e recomendadas, as orientações pré e pós-operatórias oferecidas pela equipede enfermagem, não foram relatadas pelos pacientes.
Entre as principais percepções explicitadas pelo grupo quanto aos procedimentos invasivos, ressaltaram-se o desconforto causado pela sonda nasogástrica, o medo da dor e dos drenos. Resultados não esperados, tais como o medo do atendimento da equipe e de ser assistido por profissionais mal preparados, foram também encontrados.

Em virtude deste estudo ter se realizado em hospital público, onde a maioria dos pacientes entrevistados possuia nível educacional menos favorecido, recomenda-se a realização de outras investigações que possam evidenciar percepções quanto aos procedimentos invasivos, entre clientela de nível educacional mais elevado.

\section{REFERÊNCIASBIBLIOGRÁFICAS}

1 - BARBosA, H. Controle clínico do paciente cinurgico. 5 ed. Rio de Janeiro, Săo Paulo: Livraria Atheneu, 1986.

2 - BIROLINI, D. Infecção e procedimentos invasivos. IN: FERRAZ, E.M. (Org.) Manual de controle de infecção em cirurgia. São Paulo: EPU, 1982.

3 - BOGOSSIAN, E. Manual prático depré e pós-operatório. Rio de Janeiro: Ed. Médica e Científica Ltda 1987.

4 - BRASIL. Instituto Nacional de Assistência Médica e Previdência Social. Tabelas de grupos e procedimentos. Brasília: DATAPREV, 1984.

5 - BRUNNER, L.S. \&SUDDARTH,D.S.Enfermagem MédicoCirúrgica. Rio de Janeiro: Interamericana, 1977.

6 - FERRAZ, E.M. (Org.) Manual de controle de infecção em cirurgia. Săo Paulo: EPU,1982.

7 - HOOK, E.W. Preâmbulo. IN: SURATT, P.M. \& GIBSON, R.S. (Org.) Manual de Procedimentos médicos. São Paulo: Roca, 1984.

8 - JOUCLAS, V.M.F. \& SALZANO, S.D.T. Planejamento de uma ficha pré-operatória de enfermagem. Rev.Esc.Enf. U.S.P., São Paulo, v.15, n.1, p.5-16, abr.1981.

9 - JUAÇABA, H.G. Preparação da equipe cirúrgica e do pessoal de apoio. IN: FERRAZ, E.M.(Org.) Manual; de Controle de infecção em cirurgia. São Paulo, 1982.

10 -KAWAMOTO, E.E. Enfermagem em Clínica Cirúrgica. São Paulo: EPU, 1986.

11 - KUHN, E.H., KRUSE, H.L., RUSCHEL, P P., DOVERA, T.S. Grupo de pacientes de cirurgia cardiaca - relato de experiência. Rev.Bras.Enf. Brasilia, v.39, n.2/3, p.76-80 abr/set 1986

12 -LEITE, J.L., CORREA, D.A. e FERNANDES, C.S.R. Necessidades e expectativas do paciente em pósoperatório de cirurgia cardíaca-avaliaçăo de uma abordagem prática. Rev.Bras.Enf., Brasília, v.38, n.3/4, jul/dez 1985.

13 -LUDKE, H \& ANDRÉ, M.E.D.A. Pesquisa em educação: abordagens qualitativas. São Paulı: EPU, 1986 (Temas Básicos de Educaçăo e Cultura).
14 -MENDES, I.A.C., TREVISAN, M.A., HAIASHIDA, M., SONOBE, H. M. Comunicação com o paciente: o teórico e o concreto na enfermagem de âmbito hospitalar. IN: Congresso Brasileiro de Enfermagem, 43, 1991. Curitiba. Programa... Curitiba: ABEn-Pr, 1991, p.121.

$15-\mathrm{MOSCOVICl}, \mathrm{F}$. Desenvolvimento interpessoal: leitura e exercício de treinamento em grupo. Rio de Janeiro, Livros Técnicos e Científicos,1978.

16 -ORLANDO, I.J. O relacionamento dinámico enfermeiropaciente, função, processo e principio. Săo Paulo: EPU, 1978.

17 -PAIVA. M.F.A., JORGE, S.A., KOIZUMI, M.S Procedimentos invasivos e complicaçōes em pacientes com traumatismo crâneoencefálico internados em unidade de terapia intensiva. Revista Gaúcha de Enfermagem, Porto Alegre, v.13, n.1. p.41-46, jan. 1992.

18 - PADILHA, K.G. O coronariopata e o ambiente da unidade de terapia intensiva - estudo da influéncia dos procedimentos invasivos. São Paulo, 1985. Dissertação (Mestrado) Escola de Enfermagem da Universidade de São Paulo, 1985.

19 - PASCUCCIZEN, O. \& BRUTSCHER, S. Humanização: enfermeira de Centro Cirúrgico e o paciente de cirurgia. Enfoque, vol.14, n.1,p.4-6, set. 86.

20 -PELLIZZETTI, N. e BIANCHI, E.R.F. Avaliaçăo da prescriçăo de enfermagem para o periodo transoperatório. Rev.Paul.Enf. São Paulo, ed especial, Ip. 75-84, jun. 1991. Ed. especial.

21 -RODRIGUES, A.I. O paciente no sistema centro cirúrgicoum estudo sobre percepçס̄es e opiniōes de pacientes em relação ao período transo-peratório. Rev. Esc.Enf. USP., Săo Paulo, v.18, n.2,p. 163-176, ago. 1984.

22 -ROSA, I. B. O pape! do enfermeiro em centro cirúrgico. Rev. Gaúcha Enferm. Porto Alegre, v.10, n.2, p.2532, jul. 1989.

23 -SOARES, R. Assistência de enfermagem a uma pessoa submetida a mastectomia. Enfermagem Atual, Ano II, n 11,29, p. 12 - 29, mai/jun. 1980. 
24 -TAKITO, C. Como o paciente internado percebe o ambiente que the é oferecido pelo hospital. Rev.Esc.Enf. U.S.P Săo Paulo, v.19, n.3, p.263-280,dez. 1985.

25 -TEIXEIRA, M.E.M. Relação terapéutica entre a equipe de enfermagem e o paciente submetido a cirurgias de pequeno, médio e grande portes. Rio de Janeiro, 1991. Dissertação (Mestrado), Universidade Federal do Rio de Janeiro, 1991

26 -TRIVIÑOS, A.N.S. Introđução à pesquisa em ciencias sociais: a pesquisa qualitativa em educaçăo. Săo Paulo: Atlas, 1987
27 -SALZANO, S.D.T. Os ploblemas dos pacientes detectados pela enfermeira durante a recepção no centro cirúrgico. Rev. Paul. Enf. São Paulo, v.6, n.2, p.67-77, abr./jun. 1986.

28 - URSI, E. S. e MACUL, S. F. A atuaçăo do enfermeiro do centro cirúrgico em visitas pré e pós-operatórias. Enfoque, Vol. $15 \mathrm{n}^{\circ}$ 1, p.46, jun.87.

29 - VALLE, E.G., GUEDES, M.C.V., ALBUQUERQUE, M.T. Pós-operatório de cirurgia cardiaca: o que pensam e verbalizam os pacientes. Rev.Bras.Enf., Brasília, v.43, n.1/2/3/4, p.79-84, jan/dez. 1990.

Recebido para publicação em 28/11/93 